\title{
Actores no gubernamentales ante un eventual acuerdo comercial con Estados Unidos
}

\section{Verónica Robledo AgUiRRe}




\section{Introducción}

La invitación cursada a Chile por Estados Unidos en diciembre de 1994 a convertirse en el cuarto miembro del NAFTA (North American Free Trade Agreement), dando inicio al objetivo de crear una zona de libre comercio hemisférica (ALCA), ha motivado una amplia discusión tanto a nivel gubernamental como no gubernamental a lo largo de más de tres años.

Puesto que la suscripción de un convenio comercial con Estados Unidos, ya sea un ALC bilateral (acuerdo de libre comercio) o un ingreso al NAFTA, guardaría relación con la política comercial chilena implementada a lo largo de los últimos veinticinco años, entidades no gubernamentales de los sectores empresarial, laboral y medioambiental han incorporado sus experiencias referentes a los beneficios y/o costos obtenidos como una consideración relevante al momento de exponer sus planteamientos concernientes a la conveniencia o inconveniencia de suscribir un acuerdo con Estados Unidos.

Asimismo, sus análisis han incluido observaciones en relación a los efectos propios de una mayor interdependencia internacional, en especial en lo que se refiere al escenario de asimetría política y económica derivados de un contexto de desigual distribución de riqueza y poder en las relaciones internacionales.

Al mismo tiempo, interesa destacar la participación de actores no gubernamentales a fin de ilustrar otra dimensión en la cual se ha manifestado la globalización, específicamente la política. En efecto, el Estado ha tendido a perder, al menos en parte, su otrora calidad y capacidad de conducción monopólica de las relaciones internacionales pues actores no estatales se han vuelto activos participantes en ellas, dando origen a una interacción entre ambos actores que oscila entre la cooperación y el conflicto, según sus intereses económicos, sociales y políticos.

Es así como en el marco de los intentos preliminares de materializar el inicio de las negociaciones para la suscripción de un acuerdo con Estados Unidos, agrupaciones no gubernamentales se han perfilado como destacados participantes en la discusión del tema, cuya resolución inevitablemente tendrá efectos en sus intereses sectoriales respectivos. Tambiên han posibilitado la canalización y exposición de las posturas de sus representados ante las autoridades públicas tanto del poder ejecutivo como del poder legislativo así como a otros centros de poder como una forma de comunicar, avanzar, promover o resguardar sus intereses.

El grado de intensidad en la discusión del tema, la difusión sectorial de éste, su tratamiento ante las autoridades públicas, y la gestión realizada con objeto de difundir y exponer sus intereses han variado. Igualmente, ha diferido su experiencia con el sistema político estadounidense, en el entendido de que la interrelación con centros de poder norteamericanos incide 
en las posturas de los congresistas, quienes en definitiva son los responsables de conceder o no el mecanismo de negociación de vía rápida al Ejecutivo así como de aprobar o rechazar el acuerdo que eventualmente éste negocie con su contraparte chileno.

Complementando el aporte de numerosas fuentes escritas a este estudio, se efectuaron treinta entrevistas a finales de 1996 y en el transcurso del año 1997 a representantes ambientalistas (CODEFF, Defensores del Bosque Chileno, Instituto de Ecología Política, Observatorio de Conflictos Ambientales y RENACE); empresariales (AMCHAM, ASEXMA, ASIMET, CPC, Instituto Textil de Chile, SNA, SOFOFA, entre otras); y laborales (Confederación Nacional Unitaria del Agro "El Surco", Confederación de Trabajadores del Calzado, Confederación de Trabajadores Mineros, Confederación de Trabajadores Textiles, y CUT, por ejemplo). Al mismo tiempo, se ha conocido la labor de RECHIP, red intersectorial que comprende a agrupaciones civiles, ecologistas, étnicas, sindicales y sociales, cuyo nacimiento estuvo expresamente destinado a difundir, fundamentar y canalizar la oposición frente a los tratados de libre comercio. Análogamente, se ha tomado conocimiento del trabajo llevado a cabo por Mujeres Frente a la Globalización, entidad que adopta una perspectiva de género para analizar, evaluar e informar acerca de los efectos que han tenido las modificaciones del sistema económico internacional y nacional sobre el bienestar y seguridad de los trabajadores.

\section{Breve aproximación al contexto internacional}

Una de las tendencias de las relaciones internacionales en el escenario de una creciente globalización es la interdependencia derivada del incremento y la intensificación de vínculos transfronterizos a nivel de Estados, de corporaciones multinacionales, o entre ambos.

Ha de realzarse que la interdependencia tanto económica como política conlleva costos y beneficios. Ella, entonces, no garantiza de manera alguna situaciones igualmente beneficiosas para la totalidad de los actores así como tampoco pone término a conflictos entre las partes interrelacionadas. También puede significar menor autonomía en las partes involucradas.

En definitiva, en toda relación internacional caben asimetrías en cuanto al peso que cada una de las partes tiene y ejerce dentro de ella, lo cual incide en su capacidad de influencia respecto a su contraparte.

La tendencia hacia la desregulación económica a nivel internacional, la descentralización de las actividades productivas para de esta manera aprovechar las ventajas comparativas de cada región; la internacionalización registrada en el sector de los servicios; la regionalización de la economía mundial; y el protagonismo que ha tenido la innovación tecnológica, son algunos de los rasgos de la globalización económica. Cabe añadir la liberalización de las 
economías, siendo uno de sus ejemplos el notorio aumento en los flujos de inversión extranjera directa y la intensificación de la competencia, acelerando la desaparición de ciertos sectores económicos mientras también facilita la emergencia y consolidación de otros sectores.

Por ende, los mercados y los espacios geográficos aptos para la producción así como para la inversión no se limitan exclusivamente a los territorios y fronteras nacionales ya que es posible acceder e iniciar actividades económicas en otras regiones, donde los recursos económicos, humanos, naturales y tecnológicos sean más abundantes, convenientes y/o de mejor calidad.

Junto a la dependencia, el desequilibrio y la desigualdad política y económica pueden ser identificados como algunos de los posibles costos de la globalización. De igual modo, hay que recordar que no todos los países o regiones participan de las transformaciones económicas mundiales así como no todas perciben sus beneficios. Tampoco comparten el peso y rol en dichos cambios pues mientras algunos actores pueden ser sus gestores o propulsores, otros solamente pueden responder o reaccionar ante ellos, capacidad que también difiere de un actor a otro.

En términos políticos, la globalización también se ha manifestado por medio de la creciente participación de actores no gubernamentales, como por ejemplo, organizaciones internacionales y múltiples grupos de interés. Estos han configurado focos aglutinadores, canalizadores y defensores de determinados intereses, que buscan exponer y difundir sus planteamientos a las autoridades públicas, ejercer presión así como tomar parte en el monitoreo de las decisiones que sean adoptadas a nivel estatal, lo cual apunta a la participación política de dichas agrupaciones.

Por consiguiente, los Estados se han visto llamados a una mayor apertura y flexibilidad ante el interés, capacidad organizativa, y el peso tanto social como político de las entidades no gubernamentales. En suma, las autoridades y personeros estatales requieren alcanzar una mayor articulación y comunicación con una variedad de organizaciones, cuya operación es entendida como legítima en la medida en que sus causas, finalidades y medios empleados conciten un sentido de identificación, legitimidad y respaldo entre sus miembros que es reconocido por el resto de la sociedad.

En breve, los intensos cambios producidos por y en medio de la globalización influyen en el hecho de que junto al Estado otros sectores se perfilen como actores capaces y motivados por responder a dichas transformaciones.

Específicamente, la participación de entidades no gubernamentales chilenas en el contexto de un posible acuerdo comercial con Estados Unidos se explica en parte por las repercusiones que el orden económico así como las transformaciones que en él se operan tienen en el bienestar de toda sociedad, incluidos sus intereses públicos y los específicos. 
En lo referente a Estados Unidos, este país ve al hemisferio americano como una zona de interés comercial en la década de los ochenta. Ejemplos de ello son el ALC suscrito con Canadá en 1988, la Iniciativa de las Américas de 1990, y la suscripción del NAFTA en 1992. Del mismo modo, América Latina reviste importancia para sus intereses comerciales, económicos y financieros producto del crecimiento y la expansión de mercados registrados en la región, una vez superada la «década perdida».

Sin embargo, dado que otros son los socios comerciales y los mercados prioritarios para el país del norte interesa analizar las motivaciones subyacentes en dos administraciones distintas, una republicana (la de George Bush) y la otra demócrata (la de Bill Clinton) en el objetivo de intensificar los lazos comerciales con América Latina, comenzando ello con Chile.

Un punto a tener en cuenta es que América latina guarda significancia histórica y política para Estados Unidos, pues al fin y al cabo se trata de la región en la cual se ubica el país del norte. Con todo, más que señalar la precedencia de un factor por sobre otro, indudablemente en la decisión de la administración Clinton de recoger y revitalizar la propuesta Bush confluyen factores políticos y económicos.

Similarmente, en términos generales, tanto la orientación hacia el libre mercado como la reorientación hacia la democracia en la región coinciden con el liberalismo rector de la política exterior estadounidense.

Desde una perspectiva más general, la pérdida del peso político y la hegemonía relativa de Estados Unidos en el ámbito mundial incide en su deseo de procurar recuperar parte de ésta. Reforzar lazos con América Latina, en este caso los de tipo comerciales, incentivarían una mayor cercanía y fluidez en sus relaciones, lo que podría cimentar parte del poder estadounidense. Sin embargo, esto dista de sugerir que esta área sea de importancia crucial para el país del norte pues recuperar poder es un objetivo que no depende de dicho acuerdo comercial.

Por otra parte, el contexto de globalización apunta a una mayor competencia, lo cual también se da para Estados Unidos, tomando en cuenta las pretensiones de Canadá así como de la comunidad europea de vigorizar los lazos comerciales con América Latina, comprendiendo el potencial mercado de 850 millones de consumidores que esta área geográfica puede implicar para sus exportaciones.

Concretamente, existen reales riesgos para el país del norte de verse afectado por cuadros de desviación de comercio pues claramente los países prefieren realizar intercambios comerciales con aquellos socios con los cuales haya acordado términos, reglas, derechos y obligaciones, por un lado, y reducciones arancelarias, por otro. En este sentido no ha de olvidarse los acuerdos suscritos entre Chile y Canadá, así como la asociación de Chile al MERCOSUR.

Lograr materializar una zona de libre comercio hemisférica, comenzando ello con Chile, reafirmaría las posibilidades estadounidenses de incrementar sus exportaciones, las cuales 
son de primera importancia al revitalizar la actividad empresarial interna. Paralelamente, se podrían generar más y mejor remunerados empleos dentro de Estados Unidos. De manera significativa, el crecimiento económico de ese país está relacionado a su comercio exterior.

Sin lugar a dudas, el cumplimiento del compromiso asumido por la administración Clinton ante 33 países latinoamericanos y caribeños durante la Cumbre de Miami de 1994 repercutiría directamente en la credibilidad del estímulo y apoyo estadounidense hacia el libre comercio. En consecuencia, el incumplimiento de esa propuesta podría convertirse en un elemento negativo en la imagen proyectada en la región.

Adicionalmente, el regionalismo se presenta como una alternativa atractiva para un actor internacional consciente de la influencia y poder detentados por otros actores europeos y asiáticos. En breve, Estados Unidos también ha valorado los beneficios del regionalismo, lo cual, ha de enfatizarse, no significa su renuncia al multilateralismo. Ello ya que ambas modalidades de integración no son necesaria ni irrefutablemente antagónicas entre sî; por el contrario, bien pueden ser complementarias entre sí.

Concretar un acuerdo con Chile, por lo tanto, representaría un primer paso en la búsqueda por materializar el ALCA como también enviaría señales de reconocimiento a aquellos países encaminados hacia el libre comercio y la democracia. Además ello se haría con un país cuya recuperación de la crisis de los años ochenta fue más rápida que en comparación a otros países latinoamericanos y cuya disposición a liberalizar su comercio precedió al compromiso del resto de los países de la región.

\section{Reflexiones en torno al intento de emprender negociaciones comerciales con Estados Unidos}

Centrando la atención en el proceso decisional y de formulación de políticas públicas estadounidense, éste está estrechamente vinculado con la cabida que el sistema político brinda a los intereses especiales y específicos de diversos sectores de la sociedad nacional. Esto no se circunscribe a meras estipulaciones formales y teóricas resguardadas en la Carta Fundamental, sino que encuentra su expresión práctica por medio de canales de vinculación establecidos entre el Estado y la sociedad. Consiguientemente, los grupos no gubernamentales constituyen actores que toman parte activa en la democracia de Estados Unidos.

Cabe relacionar el fundamento de los grupos de interés así como su inclusión en el proceso de formulación de políticas con el concepto de democracia pues permite comprender las fuerzas que la sustentan. Lógicamente, tal nexo encuentra su respaldo en el deber del sistema político de abrir y de mantener canales de comunicación bidireccionales hacia y desde los 
individuos o grupos organizados en el entendido de que estos últimos actúan y ofrecen un nexo entre ciertos sectores de la sociedad y representantes de las élites políticas.

Desde una perspectiva general, la importancia de los grupos de interés no estriba únicamente en la potencial presión que puedan ejercer ante determinadas materias, sino que también en la posible fuente de apoyo y adhesión que puedan brindar en relación a las políticas que dichas autoridades intenten poner en práctica.

La actividad de todo grupo de interés halla su fundamento en los derechos de libre pensamiento, expresión, petición y reunión resguardadas por la Constitución de Estados Unidos. Con todo, la influencia que verdaderamente pueda ejercer no depende únicamente de la naturaleza de sus exigencias ni de las tácticas escogidas para ejercer presión sino que de la receptividad de parte de las autoridades públicas. Por ende, pese a la incidencia de estas agrupaciones en el proceso político, su potencial influencia no debe ser sobredimensionada ya que serán los actores estatales quienes en definitiva determirarán la transformación o no conversión de sus peticiones en políticas públicas.

Producto de lo anterior, los actores no gubernamentales chilenos que opten por tomar parte activa en el intento de ejercer presión en el sistema político estadounidense, en virtud de que allí se resolverá la concesión o no otorgamiento de la autoridad al Ejecutivo para negociar disponiendo del mecanismo de vía rápida así como será en ese país que se diseñará y delimitará el tipo de. convenio a ser negociado, deben tomar conocimiento de la acogida que éste otorga a los intereses especiales.

En síntesis, la receptividad del sistema político estadounidense a los intereses especiales, incluida la posibilidad ofrecida a grupos extranjeros de exponer sus planteamientos, constituye un elemento que sustenta los intentos de agrupaciones no gubernamentales chilenas de comunicar, promover y/o resguardar sus intereses asociados a la posibilidad de concretar un acuerdo con Estados Unidos. Sin poder asegurar o garantizar el éxito en las tentativas de dichas entidades, al menos sí existen los canales a los cuales ellas pueden acudir.

A diferencia de lo que ocurre en Chile, la figura del lobbying está institucionalizada y reglamentada en los Estados Unidos, encontrando una de sus raíces en la Primera Enmienda Constitucional, la cual establece el derecho a peticionar al gobierno.

El lobbying puede adquirir especial importancia para las organizaciones empresariales chilenas a favor del TLC como un trabajo complementario y reforzador del efectuado por la Embajada en Washington. Ya sea mediante el ejercicio de un lobbying directo o indirecto, los servicios de profesionales especializados en la legislación de ese país, con una amplia red de contactos con representantes gubernamentales, del poder legislativo y con los medios de comunicación, son herramientas de utilidad cuando se pretende informar y dar a conocer posturas determinadas ante las autoridades públicas estadounidenses. 
Por lo tanto, los actores interesados en el desarrollo que tengan las tentativas de emprender negociaciones oficiales con Estados Unidos, deben tener en cuenta que la no institucionalización ni reglamentación de la figura del lobbying en Chile no debe llevar a menoscabar o ignorar su legitimidad, aceptación, recurrencia, peso y tradición en el sistema político estadounidense.

En otro orden, el Artículo I de la Constitución de los Estados Unidos estipula que es el poder legislativo el responsable del manejo de los asuntos comerciales mientras que es el Ejecutivo el responsable de la conducción de la política exterior.

A pesar de lo anterior, el Ejecutivo está facultado para solicitar autorización al poder legislativo para negociar reducciones arancelarias, vía el mecanismo de "fast track». Esta venia legislativa facilita el proceso de negociación al permitir al Ejecutivo garantizar certeza al otro país acerca de los contenidos y estipulaciones del acuerdo a ser negociado. Ello dado que la revisión de la cual será objeto ese convenio no admitirá modificaciones parciales ni totales pues el Congreso solamente podrá aprobado o rechazado como un todo.

Precisamente, una vez aprobada la concesión de la vía rápida, el Ejecutivo está llamado a iniciar consultas al Congreso, al sector privado y a la sociedad en general en lo que atañe a la postura que el United States Trade Representative (USTR) -agencia que puede ser descrita como la institución líder del poder ejecutivo en el tratamiento y manejo de la política comercial- debe asumir en torno a la agenda de la negociación.

Puesto que los intereses extranjeros pueden ser presentados ante las autoridades públicas durante esta fase, la labor que pueda ser llevada a cabo por los representantes no gubernamentales chilenos que opten por avanzar sus intereses directamente en Washington tienen un canal de comunicación disponible. De todas maneras, esto no debe llevar a desconocer que tener acceso a los comités especializados del USTR y/o legislativos es una oportunidad que requiere de las habilidades y de la experiencia de un eficaz lobbying a raíz de los numerosos actores estatales como no estatales que toman parte en el proceso de discusión de la política comercial en ese país.

Relacionado a que el sistema decisional estadounidense es amplio y difuso, un acuerdo esencialmente comercial no se ha limitado ni lo hará a futuro, a un debate netamente de esa naturaleza, al ampliarse la discusión en el Congreso estadounidense a la diversidad de intereses nacionales. Ello torna más lento e incierto el tratamiento del tema, como se ha verificado por la influencia ejercida por representantes ambientalistas y sindicales estadounidenses, cuyas exigencias de que sus reinvidicaciones sean incorporadas al cuerpo central del NAFTA, en vez de permanecer incluidos en los anexos respectivos, ha dividido a congresistas.

Uno de los aspectos relevantes es el que dice relación a los centros de poder en Estados Unidos. Junto al poder ejecutivo y al legislativo, los grandes medios de comunicación, las 
agencias y oficinas de lobbyistas profesionales, y los «think tanks», centros de investigación que aportan antecedentes e información sobre materias públicas, tienen innegable influencia en la vida política estadounidense.

Por otra parte, los numerosos intereses y materias domésticas que centran la atención de los estadounidenses así como las prioridades internacionales atendidas por su política comercial y exterior vuelven aún menos factible que Chile se convierta en foco de interés y que se mantenga como tal en el tiempo. Es así que se perfila como un desafío para los actores no gubernamentales chilenos la presentación y difusión de sus posturas así como la periódica comunicación de antecedentes ante representantes del poder ejecutivo y legislativo norteamericanos como también a los ya mencionados centros de poder.

Particularmente, en momentos en que durante 1997, por ejemplo, se registraba en Estados Unidos la percepción de que si bien la entrada en vigor del NAFTA no había provocado la pérdida de innumerables puestos de trabajo como originalmente habían temido algunos sectores, tampoco habla reportado los beneficios que se habían previsto en el ámbito comercial y laboral. Esa apreciación, sumado a que el informe que por ley debió presentar la administración Clinton al Congreso en julio de ese año acerca de los efectos de dicho TLC ha expuesto un entusiasmo cauto y moderado, sugiere que aún resta labores informativas y persuasivas de las agrupaciones chilenas que respaldan el acceso al NAFTA, y de las agrupaciones que lo rechacen, por otra.

\section{Postura y participación de actores no gubemamentales: reflexiones y desafios}

Una vez revisada la postura y el rol desempeñado por entidades no gubernamentales en el marco de las conversaciones preliminares con Estados Unidos tendientes a un ALC, destaca la influencia ejercida por la globalización. Lejos de reducirse a un simple entorno en particular en el cual se desenvuelven las relaciones internacionales, ella configura un proceso que a raíz de sus amplias implicancias multidimensionales desencadena variadas apreciaciones y reacciones en esos grupos.

Como fuera señalado, la inserción económica internacional de Chile ha coincidido con la globalización en términos de su tendencia al libre comercio, la desregulación económica, la recepción y distribución de inversión extranjera, el incremento y diversificación de sus exportaciones, y el desmantelamiento de un rol tutelar del Estado. A la vez, la estimulación de la actividad del sector privado, la desaparición de actividades productivas no competitivas, la reestructuración de algunas así como la creación de otras, la implementación de una política 
arancelaria neutral y de bajo nivel de protección, y la diversificación de mercados son rasgos primordiales de la evolución experimentada en el ámbito comercial y económico, los que han reforzado la aptitud de Chile para acceder a ALCs.

Junto a ello, Chile ha optado por la combinación de estrategias unilaterales, bilaterales, regionales y multilaterales con el propósito de acceder a diversos mercados, resguardarse ante posibles olas proteccionistas, ampliar el acceso a mercados más convenientes, y reducir riesgos de dependencia.

El ingreso de Chile al NAFTA o la suscripción de un acuerdo bilateral con Estados Unidos, lejos de apartar al país de las directrices que han guiado sus relaciones económicas internacionales, guardaría plena coherencia con su política de regionalismo abierto, la cual se ha traducido en su esfuerzo por procurar convenios con diversos países en vez de restringir sus intercambios comerciales con pocos socios.

Cabe reiterar que los efectos de la política comercial chilena se han convertido en referentes de primer orden en la predisposición, acogida, receptividad y respaldo o rechazo de grupos no gubernamentales hacia el libre comercio en general, dentro del cual se insertan las opciones comerciales con Estados Unidos. Ello en vista de que un convenio con dicho país tendría plena coherencia con la apertura de la economía chilena, y por ende con la globalización, al fomentar la liberación comercial y financiera.

Desde una perspectiva más acotada, tanto el sector laboral como el medioambientalista acentúan las repercusiones adversas que la globalización, vía la liberalización y desregulación económica, ha tenido en ellos. Notoriamente, la expansión y el fortalecimiento de empresas transnacionales en base a un exagerado aprovechamiento de ventajas comparativas repercuten en su reticencia respecto a las pretensiones gubernamentales y empresariales de profundizar la apertura económica.

La explotación de recursos naturales abundantes y de relativo bajo costo, por una parte, así como de una mano de obra económica, por otra, dificultan las aspiraciones de orientar el desarrollo y el crecimiento económico del país según las directrices de un desarrollo sustentable y de un crecimiento justo. A su juicio, los beneficios obtenidos por esas corporaciones transnacionales no han sido compartidos por el país anfitrión. A la vez, la desprotección ambiental, laboral y social con las cuales el Estado ha respondido a la globalización motiva sus críticas.

Entidades medioambienfalistas, tales como RENACE, Instituto de Ecología Política, Observatorio de Conflictos Ambientales, y una agrupación intersectorial RECHIP, han reiterado que la insistencia en basar las exportaciones en recursos naturales agudiza tanto la vulnerabilidad como la insuficiente sustentabilidad del modelo chileno. Por un lado, se está sujeto a fluctuaciones de precios que caracterizan al mercado internacional de los bienes primarios o 
semi elaborados y, por otro lado, no se ha resuelto la no internación de los costos de actividades productivas que hacen uso del medio ambiente y lo contaminan.

Desde el punto de vista de representantes ecologistas, cualquier acuerdo a intentar con Estados Unidos que adopte al TLC de América del Norte como modelo significaría dejar irresueltas las falencias de la normativa ambiental nacional toda vez que no estipularía modificaciones en ella. Además, en virtud de la composición de las exportaciones al mercado estadounidense, preocupa la insistencia en materias primas con bajos grados de elaboración al afectar tanto al ecosistema como a las fuentes de recursos naturales y al mantener un cuadro de vulnerabilidad. De esta forma, el sector teme continuar con lo que ellos han percibido como una insuficiente preocupación por el medio ambiente.

Coincidiendo con lo expresado por sus pares estadounidenses, las organizaciones ambientalistas chilenas cuestionan el tratamiento del tema medioambiental por parte del NAFTA a nivel de anexo, el Acuerdo de Cooperación Ambiental de América del Norte (NAAEC). La exclusión del tema del cuerpo central del TLC ha restado la necesaria urgencia de la materia. Otro aspecto que genera reparos en las entidades chilenas se relaciona a la omisión que el texto hace del cuidado y resguardo de los recursos naturales.

En el sector empresarial, en cambio, la globalización comúnmente coincide con su motivación de ampliar y de crear mercados para las exportaciones, destrabar y flexibilizar el ingreso de sus productos o servicios en ellos, vigorizar lazos comerciales y dinamizar los flujos de intercambio internacionales, y aprovechar y promover el acceso a mejores o nuevas tecnologías. De ese modo, la internacionalización es descrita por representantes empresariales a nivel de la Confederación de la Producción y el Comercio (CPC) y de la Sociedad de Fomento Fabril (SOFOFA) como procesos que brindan oportunidades adicionales para sus actividades productivas y que motivan crecientes niveles de competitividad.

Considerando que un acuerdo comercial con Estados Unidos, en combinación con otros convenios comerciales internacionales, concuerda con y reafirma la internacionalización de la economía, representantes empresariales valoran la reducción y eliminación de barreras tanto arancelarias como para-arancelarias en el intercambio comercial con la mayor economía del mundo y principal socio comercial de Chile, así como el resguardo ante una eventual exclusión de ciertos productos chilenos del Sistema Generalizado de Preferencias (SGP).

No obstante, dicho sector tiene conocimiento de que un convenio comercial con Estados Unidos reportaría mayores avances en el área financiera que en la comercial dado que las barreras que enfrentan actualmente las exportaciones chilenas en ese mercado no son de magnitud. Por otra parte, el tratamiento concedido por el texto del NAFTA y sus anexos a las materias laborales y medioambientales es respaldado ya que en opinión de representantes empresariales no desvirtuaría la esencia comercial del convenio. 
No obstante, la interpretación del tratado como una oportunidad deseable pero no crucial ha ganado fuerzas en estos últimos tres años a raíz de la suscripción de otros acuerdos comerciales internacionales o de la perspectiva de estar próximos a hacerlo. Ello, junto a los obstáculos enfrentados por la solicitud del Ejecutivo estadounidense del mecanismo de negociación de vía rápida, ha atenuado la atención que hasta 1995 cuando se produjo el primer aplazamiento en su solicitud -sí había concitado el TLC de América del Norte a nivel de organizaciones empresariales chilenas.

En cuanto a algunas observaciones planteadas por grupos empresariales, éstas se relacionan a que el intercambio comercial debe ser realizado en igualdad de condiciones, apuntando este reparo al deseo de que no persistan subsidios estadounidenses y se revierta el fuerte déficit comercial que afecta a Chile. Tampoco se tiene certeza respecto a la factibilidad de que un convenio con Estados Unidos conduzca necesariamente a la segunda fase exportadora pues la naturaleza de las exportaciones chilenas no sería necesariamente modificada si continúa la demanda por recursos naturales, y si a nivel interno no se hacen esfuerzos por modificar la composición de esas exportaciones.

De todas formas, en base al respaldo hacia la apertura y desregulación económica y comercial, la intensificación de los intercambios comerciales, la promoción de la competitividad de sus productos, y de los mercados destinatarios de éstos, un acuerdo comercial con dicho país es interpretado por el sector empresarial como parte del curso natural de las relaciones económicas internacionales de Chile.

Por último, el propio rubro productivo de las organizaciones empresariales incide en sus posturas. Esto quiere decir, según se trate de un sector exportador o sustituidor de importaciones. En este sentido, el esperable aumento de importaciones de productos estadounidenses implicaría una creciente competencia. Esta, a su vez, bien puede beneficiar a los empresarios en la medida en que los incentivo a mejorar la calidad de sus productos y de las tecnologías empleadas, o perjudicarlo, en caso de que sea incapaz de «sobrevivir» en ese cuadro de competencia por razones de rezago tecnológico o de capital.

Al revisar las posturas del sector laboral, en tanto, se desprende que los reparos formulados hacia el NAFTA guardan relación con su percepción acerca del modelo económico, al ver en un acuerdo como ese una continuidad de los lineamientos que lo han orientado. Fundamentalmente, este sector cuestiona el aprovechamiento de ventajas comparativas y de normativas relativamente flexibles, así como deficiencias en la distribución de los beneficios logrados por medio del crecimiento económico.

Igualmente, el NAFTA es percibido como un acuerdo que tiende a privilegiar a las empresas transnacionales, a las cuales interesa la libre movilidad del capital y el libre uso de recursos naturales. Además, dado que el TLC no exige modificaciones a la normativa laboral 
chilena, se requiere introducir cambios y mejorar el código laboral chileno, en especial en lo concerniente al derecho a la sindicalización y a la negociación colectiva, lo cual ha obstaculizado -hasta 1997, al menos- el cumplimiento de los convenios 87 y 98 de la Organización Internacional del Trabajo, lo cual incide en un debilitamiento en el poder negociador de los trabajadores. Es más, la Central Unitaria de Trabajadores (CUT) insiste que las normas laborales descritas en los convenios de la OIT deben constituir las bases mínimas y obligatorias de cualquier convenio comercial con objeto de garantizar el resguardo social de los trabajadores.

Paralelamente, las agrupaciones laborales chilenas rechazan el anexo pertinente a la materia laboral, el Acuerdo de Cooperación Laboral de América del Norte (NAALC), pues, entre otros aspectos, tampoco alteraría ni estipularía las normativas laborales nacionales. Consiguientemente, en su opinión, las reinvidicaciones de los trabajadores quedarían relegadas a acuerdos débiles y de insuficiente peso.

Los trabajadores organizados de los rubros textil, del calzado y del cuero, y agrícola, son quienes mayoritariamente desaprueban la apertura económica internacional efectuada en el marco de una competencia desleal y de exclusión de cláusulas sociales del cuerpo central del NAFTA.

Interesante ha sido constatar la percepción de que la globalización, por medio de la puesta en práctica del modelo económico y de su orientación hacia la rubricación de convenios comerciales internacionales, ha conllevado un proceso de "feminización de la pobreza". Así, trabajadoras del rubro textil, del calzado y agrícola, particularmente, han identificado a la desprotección e inseguridad laboral, los vacíos y falencias en la normativa laboral nacional y algunas transformaciones como elementos adversos. Similarmente, preocupa la persistencia del despido sin causal, el contrato flexible, y la subcontratación, a juicio de Mujeres Frente a la Globalización, entidad que opera desde 1997. A la vez, las grandes privatizaciones, los procesos de transnacionalización y la reducción en el rol del Estado en el ámbito del bienestar social y de la salud producen inquietud. Al ver en un ALC con Estados Unidos o en una inserción al NAFTA una expresión de la globalización así como una prolongación del modelo económico, se teme que los impactos negativos sean acentuados.

Asimismo, se cuestiona la calidad del trabajo que un convenio comercial podría crear pues es esperable que potenciales nuevos trabajos se centren en el rubro de los recursos naturales. En ese caso, disminuirían las posibilidades de promover una fuerza laboral más entrenada y capacitada que denote un intento por incorporar mayor grado de elaboración a los productos.

En síntesis, las posturas del sector laboral en torno a la eventual inserción al NAFTA o suscripción de un ALC bilateral implican más que sus respectivas evaluaciones técnicas sobre sus efectos y contenidos, al suponer un cuestionamiento al modelo adoptado por Chile, el que 
a su vez ha convergido con la globalización. Esto en lo que respecta al libre movimiento y traslado de empresas, por un lado, y la no resolución de los problemas que limitan las condiciones y la calidad de vida de los trabajadores, por otro.

Además, grupos laborales de los sectores textil, calzado, metalmecánico y agrícola, entre otros, representados por CUT, en tanto, han enfatizado que empresas transnacionales han obtenido provecho de una mano de obra más económica a costa del nivel de vida de parte de los trabajadores. Esto realza la disparidad que se observa, por un lado, en las relaciones entre países desarrollados (desde los cuales provienen la mayor parte de las empresas transnacionales) y los en vías de desarrollo (países anfitriones que desean inversión extranjera directa en sus territorios nacionales). Por otro lado, la disparidad se constata en las relaciones entre el mundo empresarial y el de los trabajadores, en lo que se refiere a la distribución de los beneficios.

Buscando el resguardo de los trabajadores, en 1996, durante la celebración del Congreso laboral Canadiense, la CUT y su contraparte canadiense, a Canadian Labor Congress (CLC), propusieron la inclusión de cláusulas sociales en los acuerdos comerciales internacionales. Así existiría un compromiso solemne respecto a los principios básicos que debían, ser reconocidos en el área social así como debían ser garantizados por los Estados participantes. Ha de añadirse, que también acordaron abogar por la inclusión normativa de protección al medio ambiente con el propósito de asegurar la seguridad en el lugar de trabajo.

La CUT ha intentado reforzar los lazos tanto con las agrupaciones pares canadienses como con las estadounidenses, motivado ello por su deseo de incluir dichas cláusulas sociales en los convenios internacionales de libre comercio, lo cual por consiguiente se hace extensivo a su postura frente al TLC de América del Norte. Mediante acuerdos firmados con el Canadian Labor Congress y la American Federation of Labor-Congress of Industrial Workers (AFL$\mathrm{CIO}$ ), la entidad chilena ha formalizado sus exigencias de velar por el derecho a la libertad sindical y a la negociación colectiva. Al mismo tiempo, mediante un acuerdo, la CUT y la AFL-CIO solicitan conjuntamente que las negociaciones sean llevadas a cabo bilateralmente para así tomar en cuenta las circunstancias particulares de cada nación.

En resumen, la participación de las agrupaciones laborales ha supuesto dos planos. Por una parte, ha priorizado la ampliación y difusión de la discusión en torno a la globalización y a los tratados comerciales internacionales a nivel de los trabajadores, al concebir la educación de éstos como elemento indispensable en el intento de un mayor análisis y peso en el debate nacional. Por otra parte, mediante nexos con agrupaciones pares como la CLC y la AFL-CIO, representantes laborales se han incorporado a la discusión internacional relativa al descuido percibidos de los convenios comerciales. Mediante la creación de alianzas, la CUT ha hecho llegar al Congreso norteamericano sus exigencias de resguardar esas cláusulas sociales y laborales. El consenso convenido con entidades pares procura fortalecer el peso de las observa- 
ciones formuladas por los trabajadores ante el tema de los tratados comerciales tanto al interior del país como ante foros y organismos internacionales.

A las diferencias suscitadas en el plano de las percepciones de organizaciones ambientalistas, empresariales y laborales en cuanto a los efectos previstos en un convenio con Estados Unidos, ha de añadirse las discrepancias referentes a la modalidad del acuerdo a ser negociado. Si bien la invitación extendida a Chile en diciembre de 1994 era explícitamente la de integrarse al NAFTA, con el curso del tiempo se ha discutido la posibilidad de suscribir un acuerdo bilateral.

Agrupaciones no gubernamentales chilenas han diferido en cuanto a la modalidad del acuerdo dependiendo de su aceptación o rechazo hacia el tratamiento que el texto del NAFTA, incluidos sus anexos NAAEC y NAALC, otorga a sus áreas de interés. Aunque las implicancias de una u otra modalidad difieren significativamente una de otra, ha de advertirse que su discusión involucra una perspectiva teórica pues será el país del norte el que finalmente delimitará y propondrá el tipo de convenio a ser negociado.

Mientras que agrupaciones empresariales tienden a respaldar el NAFTA, las organizaciones laborales y medioambientales aprobarían un ALC bilateral, bajo el supuesto de que ese tipo de convenio acogería cláusulas sociales. Sin embargo, cabe preguntar si la administración estadounidense estaría verdaderamente dispuesta a apartarse decididamente del patrón del NAFTA en un acuerdo bilateral, teniendo en cuenta que dicho convenio de todas formas dependerá de la aprobación del Congreso. Prosiguiendo con esta línea argumentativa, la oposición de los republicanos a vincular los temas del libre comercio y del medio ambiente puede ser vista como una constante en la receptividad de los legisladores frente al tema del libre comercio.

Junto a los debates en que han tomado parte varias entidades ecologistas nacionales, sus vinculaciones con organizaciones pares de los países miembros del TLC de América del Norte han proporcionado antecedentes de quienes han experimentado directamente las consecuencias de este tratado. Esa información, a su vez, ha profundizado el rechazo y los reparos que muchos de los aspectos del NAFTA despiertan en representantes medioambientalistas chilenos.

Por medio de la creación de la Red Chile de Acción por Una Iniciativa de los Pueblos (RECHIP) en 1991, varias agrupaciones no gubernamentales nacionales han coordinado su exposición y difusión de reacciones que en ellas merece la Propuesta Bush, inicialmente, y el NAFTA, posteriormente. Abarcando más allá de agrupaciones ambientalistas propiamente tal, al involucrar un trabajo conjunto con las de tipo agrícolas, civiles, laborales y sociales chilenas, la operación de esta red refleja la inquietud de diversas organizaciones, por canalizar y difundir sus apreciaciones respecto a los efectos por ellas previstos en un ALC con Estados Unidos. 
Es así como RECHIP ha concebido como una prioridad educar a la población para así extender la comprensión y el pronunciamiento civil sobre el tema. Así ha ocurrido, entre otras, con el Instituto de Ecología Política (IEP) y con la Red Nacional Ecológica (RENACE). Además, RECHIP ha informado tanto a la opinión pública como al Gobierno respecto a los riesgos que la mantención y la profundización de la actual política comercial tendría sobre el ecosistema y los recursos naturales.

Las organizaciones aunadas en RECHIP han establecido nexos con sus pares estadounidenses, mexicanos y canadienses con la finalidad de proponer un marco alternativo de comercio y específicamente de regulación de inversiones así como promover las peticiones de la ciudadanía sobre los TLCs.

De todas maneras, ha de recalcarse que la vinculación con esas agrupaciones pares no se ha dado únicamente por medio de la red de contactos de RECHIP. A modo de ejemplo, CODEFF tiene su propio sistema de relaciones con entidades afines, entre ellas Friends of the Earth, World Wide Fund (WWF), Sierra Club, todas ellas estadounidenses, y con el National World Fund de Canadá. Defensores del Bosque Chileno, por otra parte, mantiene lazos con el Sierra Club, WWF, Conservation lntenational y la Western Rain Forest Alliance.

RECHIP ha contemplado como meta educar a la población acerca de la naturaleza, significado e implicancias del TLC de América del Norte, conformar una coalición nacional con nexos internacionales y el de avanzar la Carta Ciudadana, la cual expondría los planteamientos y las posturas de la comunidad civil frente al tema. En cuanto a las líneas de acción a ser emprendidas según las fases del proceso de negociación ellas consisten en sugerir un tratado alternativo, monitorear el curso de las negociaciones y reforzar la coalición.

Para la eventual etapa de aprobación de un TLC con Estados Unidos que siga el modelo NAFTA, RECHIP planea reiterar ante legisladores su solicitud a que se sumen a su rechazo hacia dicho esquema comercial. De ello se desprende la convicción de que el lobbying es un área en la cual innovar. Asimismo, propone exponer la preocupación civil hacia el tratado y denunciar sus omisiones ante el Ejecutivo y/o Legislativo.

Por último, para la eventual etapa de su entrada en vigencia, RECFIP propone monitorear sus impactos y abogar por su derogación así como efectuar campañas internacionalmente articuladas para resguardar derechos que pudieran verse amenazados.

A nuestro juicio, este sistemático plan de definición de objetivos, tareas y actividades refleja plena comprensión de que la participación de organizaciones no gubernamentales ante el NAFTA, no se limita a su discusión previa ni a su posterior negociación. Este plan realza una visiốn de largo plazo acerca de las varias líneas de acción que podrían ser puestas en práctica en las etapas preliminares y subsiguientes al proceso de negociación con objeto de defender y avanzar intereses en el marco de un posible acuerdo comercial internacional. 
Revisando la postura del sector empresarial, el consenso que la política comercial chilena concita en un considerable segmento de éste facilita y estimula un mayor acercamiento y la noción de compartir un «lenguaje común» con el sector gubernamental en esta materia. Del mismo modo, dado los efectos directos del NAFTA en las esferas comerciales y financieras lógicamente sus representantes han tomado parte activa en la discusión del tema, muchos de los cuales incluso comenzaron a debatir la perspectiva de suscribir un ALC con Estados Unidos una vez conocida la Iniciativa de las Américas en 1991.

Sobresale la labor realizada por la Cámara Chileno-Norteamericana de Comercio (AMCHAM). Ya en 1992, dos años antes de la invitación que Estados Unidos extendiera a Chile, la entidad había creado su Oficina para un Acuerdo de Libre Comercio, la cual fue concebida con la expresa finalidad de promover un ALC con el país del norte.

Del mismo modo, AMCHAM ha gestionado el contacto con varios de los congresistas estadounidenses representantes de los estados desde los cuales provienen las casas matrices de sus empresas socias establecidas en Chile. De esa manera, ha dado a conocer su deseo e interés por la concreción de un ALC, intentando informar acerca de los beneficios que ello brindaría a las empresas estadounidenses y respecto a la desviación de comercio que actualmente afecta a esas compañías en un contexto en el cual Chile ya ha suscrito acuerdos de libre comercio con Canadá y con México. Paralelamente, ha procurado dar a conocer la situación comercial chilena así como ha expuesto y comunicado estadísticas relativas a las exportaciones que cada uno de los estados del país del norte hace a Chile.

Además, AMCHAM ha realizado lobbying indirecto, contactando a staffers y representantes de congresistas. Similarmente, ha solicitado a las corporaciones socias a instar a sus respectivas casas matrices a enviar cartas a los legisladores estadounidenses. Respecto al lobbying directo, en 1995, mientras la entidad intentaba persuadir al Congreso estadounidense acerca de la conveniencia de conceder la facultad de fast track al ejecutivo, la entidad estableció contactos con miembros del House of Representatives Ways and Means Committee (Comités de Medios y Arbitrios) así como con el Subcomité de Comercio.

A nivel de la CPC, en tanto, ya a comienzos de la década, motivada por la Iniciativa de las Américas de George Bush, había solicitado la realización de estudios sectoriales acerca de los efectos que un ALC con Estados Unidos tendría. De igual manera, había gestionado el intercambio de experiencias con entidades pares estadounidenses, como la Asociación de Industriales y la Cámara Norteamericana de Comercio, así como con legisladores de Estados Unidos. También había creado PEPALC, Programa de Estudios para un Acuerdo de Libre Comercio entre Chile y Estados Unidos.

Prosiguiendo con el sector empresarial, SOFOFA ha mantenido contacto tanto con la Cancillería como con la Dirección de Relaciones Económicas Internacionales mediante la desig- 
nación de un Coordinador y una Secretaría Técnica, siendo puntos prominentes de análisis los programas y los calendarios de desgravación arancelaria así como las reglas de origen.

Esta organización propiamente tal no ha recurrido a la contratación de profesionales especializados en el lobbying en Estados Unidos en base a la convicción de que en términos generales la imagen nacional proyectada en ese país ya es positiva y que el entrabamiento sufrido por la petición del ejecutivo de la vía rápida ha obedecido a motivos de naturaleza doméstica e interna de ese país.

\section{Observaciones, desafios y futuras perspectivas}

Retomando una perspectiva de análisis general, sustentando su participación en la legitimidad y en los derechos que les concede un sistema político democrático, por un lado, y en su calidad de receptores directos o indirectos de los beneficios y/o perjuicios de las transformaciones económicas, por otro, las organizaciones no gubernamentales han expuesto sus observaciones referentes a un convenio con Estados Unidos, directamente, o al menos respecto del libre comercio, a las autoridades públicas.

En cuanto al Gobierno, éste está en todo momento llamado a prestar atención y a recoger las observaciones de una multiplicidad de grupos de interés aunque ciertamente su receptividad hacia sus exigencias y demandas no es ilimitada ni independiente del tema del que se trate. No obstante, no puede ignorarlas dada su inserción en y respeto del sistema político democrático, por una parte, y su necesidad de contar con el respaldo y la aprobación de la sociedad, por otra.

Pese a lo anterior, la participación de grupos no gubernamentales en el marco de las conversaciones con Estados Unidos tendientes a un ALC, sin desconocer los antecedentes y perspectivas que han aportado frente al tema y que puedan continuar brindando a futuro, no debe interpretarse como ilimitada. Al contrario, ella no puede desvincularse de la receptividad gubernamental hacia sus planteamientos, en términos de grados de acogida. De modo similar, dicha participación no ha de ser vista aisladamente de un hecho simple pero esencial: esas organizaciones no son las encargadas ni las responsables de iniciar, conducir ni concluir negociaciones internacionales por lo cual indudablemente son los negociadores gubernamentales quienes en última instancia decidirán y definirán el curso que eventualmente sigan las negociaciones con Estados Unidos.

Tampoco ha de olvidarse el peso que la determinación que finalmente adopte la administración estadounidense tiene en la cabida concedida a las peticiones de esos grupos. Sin olvidar la incuestionable autonomía del Gobierno chileno en su libertad y opción por negociar o no un acuerdo comercial con Estados Unidos, como tampoco la del Congreso por aprobar o 
rechazar el texto del acuerdo que eventualmente sea negociado con Washington, el espacio para los intereses de las entidades no gubernamentales chilenas también está delimitado por el curso que sigan las tentativas del Ejecutivo estadounidense por contar con el mecanismo de la vía rápida. Será Estados Unidos el que finalmente estipule los términos bajo los cuales propondría negociar el convenio comercial.

De ese modo, las observaciones de entidades medioambientalistas y laborales chilenas, aunque han sido y son incorporadas al debate nacional, difícilmente podrían derivar en una acogida gubernamental que garantice mayores concesiones que las conferidas por el Gobierno norteamericano a las entidades pares estadounidenses en esas materias sin arriesgar el interés y la voluntad de Washington de negociar un convenio.

En lo referente a la ampliación del debate y la vigorización de la participación de tales grupos generadas una vez cursada la invitación de 1994 a Chile, ella guardó relación con la percepción de que ésta, a diferencia de su precursora, la Iniciativa Bush, era una propuesta comparativamente más directa y personalizado al país. Adicionalmente, los casi doce meses de puesta en marcha del NAFTA a diciembre de 1994, constituían antecedentes más concretos a los cuales prestar atención. Por consiguiente, las experiencias de Canadá, Estados Unidos y México tanto en el plano de las negociaciones como respecto a los primeros efectos de la operación del TLC, han sido recogidas en grados variables por entidades ambientalistas, empresariales y laborales chilenas en el proceso de estudio, análisis y evaluación del tema. Por lo tanto, las evaluaciones técnicas y políticas llevadas a cabo una vez conocida la Propuesta Bush han sido complementadas a partir de 1994 con el seguimiento e intercambio de información en torno a las experiencias que los países miembros del TLC de América del Norte han tenido en los últimos tres años y medio.

Sin embargo, la falta de claridad y de determinación percibidas de la administración Clinton, junto a la tardanza imperante en estos tres años y medio de intentos gubernamentales por emprender negociaciones bilaterales formales, por un lado, y la consolidación de otras opciones comerciales internacionales ante las cuales Chile ha debido definirse, por otro, han motivado un reordenamiento de las prioridades en la agenda de agrupaciones empresariales. También han implicado una revisión de los recursos y tiempo destinados al tratamiento del ALC con Estados Unidos, con excepción de la persistente estrategia de AMCHAM en relación al NAFTA.

A nivel de sectores ecologistas y laborales agrupados en RECHIP o bajo la CUT, se ha orientado la labor en base a un pormenorizado seguimiento de la evolución y de los efectos de los ALCS, en especial del TLC de América del Norte. Varios grupos han proseguido la discusión acerca del NAFTA para así ampliar el conocimiento tanto de sus representados así como el de la opinión pública. Asimismo, han destacado constantes gestiones para difundir y sistematizar un debate en torno a la necesidad de vincular el tema del libre co- 
mercio con el de las garantías en materia ambiental y laboral.

Sin embargo, asociado a la asimetría en las relaciones bilaterales, los grupos empresariales, ambientalistas y laborales chilenos que directa o indirectamente mediante nexos con sus pares norteamericanos, por ejemplo procuren comunicar y dar a conocer sus posturas e intereses en el país del norte han de aceptar un triple desafío. En primer lugar, deben lograr concitar la atención de los centros de poder que deseen contactar; segundo, necesitan superar una simple interacción con la nación estadounidense en pos de permanecer en su foco de atención por un período de tiempo prolongado; $y$, tercero, no han de ignorar que sus esfuerzos conllevan riesgos propios de un contexto en el cual definitivamente los intereses domésticos estadounidenses son los que determinarán el curso a seguir por las tentativas de dar inicio a las negociaciones bilaterales.

Igualmente, el lobbying no asegura una exitosa consecución de los objetivos fijados por las organizaciones que decidan recurrir en él.Se perfilan como requisitos sustanciales una plena comprensión acerca de las finalidades pretendidas así como acerca de la conveniencia de emplearla en un determinado período. A excepción de AMCHAM, la experiencia de agrupaciones chilenas relativas a un lobbying directo dista de representar la generalidad de casos estudiados en esta investigación.

Para concluir, la participación de entidades no gubernamentales aún se encuentra en una etapa inicial pues todavía no se han emprendido formalmente las negociaciones comerciales bilaterales. Ello sugiere que potencialmente el involucramiento de los grupos de interés puede extenderse y complementarse con el rol que asuman y las acciones que efectúen en el transcurso de etapas subsiguientes a la discusión nacional. En concreto, la firma del acuerdo, la ratificación legislativa y la entrada en marcha del convenio son fases potencialmente venideras durante las cuales se podría profundizar el estudio acerca de la relación entre dichas organizaciones y el poder legislativo y ejecutivo chileno en cuanto a la apertura, canales e instancias de comunicación. También aportaría conocimiento acerca de la función de monitoreo y de fiscalización que eventualmente podrían cumplir. A la vez, podrían extraerse antecedentes de interés en lo que atañe a la profundización, reformulación y/o redefinición de estrategias puestas en vigor con la finalidad de difundir posiciones e influir a la opinión pública. 


\section{Bibliografía / Libros}

Berry, Jeffrey M. Lobbying for the People. Princeton: Princeton University Press, 1977.

Clark, lan. Globalization and Fragmentation. Oxford: Oxford University Press, 1997.

Chelf P., Carl. Congress in the American System. Chicago: Nelson Hall, 1977.

Chomsky, Noam y Heinz Dieterich. Democracia y Mercados en el Nuevo Orden Intenacional. La Sociedad Global. Santiago: LOM Ediciones, 1996.

Destler, I.M. American Trade Politics. Washington D.C: Institute for International Economics with the Twentieth Century Fund, 1992.

Edelman Spero, Joan. The Politics of International Economic Relations. New York: St. Martin's Press, 1987.

Ercolano, Francesco. La Eliminación de las Barreras Aduaneras. Santiago: OMC, 1994.

Estudio Jurídico Quijada y Gómez. NAFTA. Libre Comercio.Santiago: M\&B Audiovisual, 1995.

Fernández, Pedro. «Los Impactos del Comercio Internacional sobre el Medio Ambiente y la Economf́a en Chile. Una Visión Desde una Organizacion No Gubernamentaly, en Chile ante el NAFTA y Otros Acuerdos Comerciales: Una Perspectiva Ambiental. Eugenio Figueroa y Marianne Shaper (Eds). Santiago: Departamento de Economía de la Universidad de Chile, 1995.

Gilpin, Robert. La Economía Política de las Relaciones Internacionales. Buenos Aires: Grupo Editor Latinoamericano, 1980.

War and Change in Word Politics.

Cambridge: Cambridge University Press, 1991.

International Encyclopedia of the Social Sciences.

David Sills (Ed.). Indianapolis:

The Macmillan Company and the Free Press, 1968. Vol. 7.

Janda, Kenneth, Jeffrey Berry and Jerry Goldman.

The Challenge of Democracy. Government in America.

Boston: Houghton Mifflin Company, 1989.

Kennedy, Paul. «To the Twenty First Century». The Rise and Fall of the Great Powers. New York: Random House, 1987.

"The American Dilemma". Preparing for the Twenty First Century. New York: Random House, 1993.
Keohane, Robert. Después de la Hegemonía: Cooperación y Discordia en la Polf́tica Económica Mundial.

Buenos Aires: Grupo Editor Latinoamericano, 1988.

Keohane, Robert and Joseph Nye. Poder e Interdependencia: La Política Mundial en Transicion. Buenos Aires:

Grupo Editor Latinoamericano, 1981.

Kissinger, Henry. «The New World Order. Diplomacy. New York: Simon and Shuster, 1994.

Kownslar, Allan and Terry Smart. "How Congress Works". American Government. New York: Webster Division MicGraw Hill Book Company, 1983.

Krasner, Stephen. Structural Conflict. The Third World Against Global Liberalism. Berkeley, Berkeley Universíty Press, 1985.

Labán, Raúl y Patricio Meller. «Estrategias Alternativas de Comercio Para un País Pequeño: el Caso Chileno». NAFTA y MERCOSUR: un Diálogo canadiense Interamericano. Richard Lipsey y Patricio Meller (Eds.). Santiago: Dolmen Ediciones, 1996.

Lanús, Juan Archibaldo. Un Mundo Sin Orillas.

Buenos Aires- Emecé Editores, 1996.

Lindblom E., Charles. El Proceso de Elaboración de Políticas Públicas. Madrid: MAP, 1991.

Ohmae, Kenichi. El Fin del Estado-Nación. Santiago: Editorial Andrés Bello, 1995.

Ornstein, Norman and Shirley Elder. Interest Groups, Lobbying and Policy Making. Washington D.C: Congressional Quarterly Press, 1978.

Paterson, Thomas. We the People. A Concise Introduction to American Politics. New York: Mc Graw Hill, Inc., 1995.

Piñeiro, Armando Alonso. El Quinto Poder. Teoría y Práctica del Lobbying. Buenos Aires: Ediciones Macchi, 1994.

Quiroga Martínez, Rayén. El Tigre Sin Selva: Consecuencias Ambientales de la Transformación Económica de Chile (19741993). Santiago. Instituto de Ecología Política, 1994.

RECHIP: Nosotras, NAFTA, Mercosur y Otras Yerbas. Santiago: RECHIP, 1997. 
Reveco, Juan Manuel. «El Tratado de Libre Comercio de América del Norte» en Chile y el NAFTA. Antecedentes, Problemas y Perspectivas, Patricio Rozas (Ed.). Santiago: Ediciones PRIES-Cono Sur, 1995.

Rosenberg, Jerry. Encyciopedia of the North American Free Trade Agreement the New American Community, and Latin American Trade. Westport: Greenwood Press, 1995.

Rozas, Patricio (Ed.). «Globalización e Internacionalización: Impactos en la Economía Chilena», Chile y el NAFTA. Antecedentes, Problemas y Perspectivas. Santiago: Ediciones PRIESCono Sur, 1995.

Servicio Informativo y Cultural de los Estados Unidos de América. Perfil del Gobierno Norteamericano. 1994.

Shiff, Maurice y Claudia Sapelli (Eds.). Chile ante el Acuerdo de Libre Comercio Versus Liberalización Unilateral. Santiago: CINDE, 1994.

The Economics and Statistics Administration Bureau of the Census. The American Almanac. Statistical Abstract of the United States (1996-1997). Section 28, Foreign Commerce and Aid, Austin: Hoover's Inc. 1996.

Thurow, Lester. La Guerra del Siglo XXI.

Buenos Aires: Javier Vergara Editor, 1992.

«Una Economía Global». El Futuro del Capitalismo.

Buenos Aires: Javier Vergara Editor, 1996.

Tomassini, Luciano. "El Estado en el Marco del Proceso de Globalización", Las Reformas deI Estado y las Políticas Públicas. Santiago: Centro de Análisis de Polfticas Públicas de la Universidad de Chile, 1994.

Tugores Ques, Juan. Economía Internacional e Integración Económica. Madrid: Mc Graw Hill, 1994.

United States Government. United States Code.Vol. 9, title 19. Washington D.C: United States Government Printing Office, 1995.

Watson, Richard. Democracia Americana. Logros y Perspectivas. Ciudad de México: Editorial LIMUSA S,A de C.V, 1989.

Weintraub, Sidney. NAFTA: What Comes Next?. Washington, D.C: Center for Strategic and International Studies, 1994.
Vilkinson, Bruce. «EI NAFTA en la Economía Chilena: Lecciones para América Latina». NAFTA y MERCOSUR. Un Diálogo Canadiense-Latinoamericano. Santiago: Dolmen Ediciones, S.A., 1996.

\section{Revistas Especializadas}

Agosin, Manuel. «Beneficios y Costos Potenciales para Chile de los Acuerdos de Libre Comercion. Estudios Püblícos. Santiago: Centro de Estudios Públicos, Núm. 52, primavera 1993.

Alburquerque, Mario. "Implicancias del Factor Laboral en un Eventual Tratado de Libre Comercio con Estados Unidos". Papeles de Trabajo, Programa de Estudios Prospectivos. Núm. 43, Noviembre de 1994.

Ale Yarad, Jaime. «La Industria Chilena Frente a las Nuevas Tendencias Económicas Mundiales». Diplomacia. Santiago: Academia Diplomática, Núm. 60, Diciembre de 1992.

Aninat, Augusto. «Las Grandes Tendencias en el Escenario Económico Internacional». Diplomacia. Santiago: Academia Diplomática, Núm. 65, Septiembre de 1994.

Banco Central de Chile. Indicadores de Comercio Exterior. Gerencia de División Comercio Exterior y Cambios Internacionales. Santiago, diciembre de 1996.

Bergsten, Fred. «Giobalizing Free Trade». Foreign Affairs. New York: Council on Foreign Relations Inc. Num. 3. Vol. 75, May/ June 1996.

Centro de Estudios Públicos. "Chile y el NAFTA" (memoria de mesa redonda). Estudios Püblicos.

Santiago: Centro de Estudios Públicos. Núm. 57, 1995.

Escobar Cerda, Luis «La Ronda Uruguay, Las Negociaciones Comerciales Internacionales». Diplomacia.

Santiago: Academia Diplomática de Chile. Núm. 49, Año 1989.

Herrera, Eduardo. «El Nuevo Orden de las Relaciones Internacionales». Diplomacia. Santiago: Academia Diplomática de Chile. Núm. 64. Junio de 1994.

Instituto de Estudios Internacionales de la Universidad de Chile. "Chile, NAFTA y el Medio Ambiente" (documento de seminario Internacional). Año XXVIII, abril-junio de 1995, Núm. 110. 
Figueroa, Carlos. "Los Nuevos Desafíos de la Inserción Internacional de Chile".Diplomacia.Santiago:

Academia Diplomática de Chile. Núm. 65. Septiembre de 1994.

Jara, Alejandro. «Término de la Ronda Uruguay. Nace la Organización Mundial de Comercion. Diplomacia.

Santiago: Academia Diplomática de Chile. Núm. 65.

Kuri Gaytán, Armando. «La Globalización: Hacia un Nuevo Tipo de Hegemonían, Revista de Comercio Exterior. V6l. 42. Núm. 12. Ciudad de México, 1992.

Larrain, Felipe y Paola Assael. «Integración Comercial Selectiva, El Caso de Chile». Estudios Públicos. Núm. 46, otoño de 1992, Santiago, Centro de Estudios Públicos.

Lederman Horwitz, Daniel. «Las Negociaciones del NAFTA. Algunas Lecciones para Chile». Diplomacia. Santiago: Academia Diplomática de Chile, Núm. 66. Diciembre de 1994.

Meller, Patricio «Revisión y Discusión de las Políticas Comerciales de Chile», Integración y Desarrollo. Instituto para la Integración de América Latina y el Caribe, Banco Interamericano del Desarrollo.Enero - Abril de 1996.

Moneta, Carlos J. «Los Procesos de Globalización, Reflexiones sobre la Evolución del Sistema Mundial», Estudios Internacionales. Santiago: Instituto de Estudios Internacionales de la Universidad de Chile. Año XXIII. Núm. 106. Abril-Junio 1994.

Moyano Berríos, Eduardo. "La Apertura Comercial de la Economía Chilena", Diplomacia. Núm. 67. Marzo de 1995.

Opoku Awuku, Emmanuel. «How Do the Results of the Uruguay Round Affect the North-South Trade?».

Joumal of World Trade. Vol. 28. Num. 2. April 1994.

Pastor, Robert. «The Clinton Administration and the Americas: the Postwar Rhythm and Blues».Joumal of Interamerican Studies and World Affairs. Miami: North-South Center Press, University of Miami.Vol, 38.Num. 4. Winter 1996-1997.

Tomassini, Luciano. «El Proceso de Globalización y Sus Impactos SocioPolíticos». Estudios Internacionales. Instituto de Estudios Internacionales de la Universidad de Chile. Año XXIX, julio-septiembre de 1996, Núm. 115.

VanGrasstek, Craig. "is the Fast Track Really Necessary?". Journal of World Trade. Vol. 31, Num. 2, Apñl 1997.
Walker Errázuriz, Francisco. «Aspectos Laborales del Tratado de Libre Comercio entre Estados Unidos, Canadá y México, NAFTA en Relación con la Incorporación de Chile», Diplomacia. Núm. 68, Junio-Diciembre de 1995.

\section{Documentos}

Campusano, Raúl y Pablo Heilenkötter.

Nafta y Mercosur. Descripción de Tratados.

Santiago: Friedrich Naumann-Stiftung, 1995.

Coeymans, Juan Eduardo y Felipe Larrain.

Tratado de Libre Comercio entre Chile y Estados Unidos.

Daher, Antonio. Tratados y Exportaciones Regionales.

Serie Documentos de Trabajo. Santiago: Centro de Estudios Públicos, Núm. 255, Agosto de 1996.

Confederación de la Producción y el Comercio, 1992

Figueroa, Eugenio. El Medio Ambiente en el Tratado de Libre Comercio de América del Norte. Santiago: Centro de Economía Internacional y Desarrollo, Universidad de Chile, 1995.

Guerra-Mondragón, Gabriel. «El Lobby en los Estados Unidos». Estudios Norteamericanos. Boletín núm. 3. Santiago: Instituto de Ciencia Política de la Universidad de Chile, 1995.

Leiva, Fernando. en «Tratado de Libre Comercio y Modelo Neoliberal». Santjago: RECHIP, 1994.

Lortie, Marc. Seminario «Negociando con los Estados Unidos». Estudios Norteamericanos. Boletín núm. 1. Santiago: Instituto de Ciencia Política de la Universidad de Chile, 1994.

Martinovic A., Héctor. Acuerdo de Libre Comercio Chile Estados Unidos: 2 .Estrategia Comercial de una Segunda Fase Exportadora?.Papeles de Trabajo. Santiago:

Corporación Tiempo 2000. Núm. 26. Noviembre de 1993.

Morales, María Eugenia. «¿Donde Está Chile en Su Camino al NAFTA?». Seminario «Negociando con los Estados Unidos». Estudios Norteamericanos. Boletín núm. 3. Instituto de Ciencia Política de la Universidad de Chile, 1994.

Navarrete, Jorge Eduardo. "Algunos Aspectos de la Experiencia de México en la Negociación del Tratado de Libre Comercio de América del Norte". Seminario "Negociando con los Estados Unidos". Estudios Norteamericanos. Boletín núm. 1. Instituto de Ciencia Política de la Universidad de Chile, 1994. 
Ruiz-Tagle, Jaime. "La Integración Regional y el Ingreso al NAFTA". Economía y Trabajo, 5to Informe Anual. Santiago: Programa de Economía del Trabajo, 1994/1995.

Van Hauwermeiren, Saar: «NAFTA y Medio Ambiente», Conferencia Nacional e Internacional Frente al NAFTA: Hacia la Carta Ciudadana. Santiago: RECHIP, 1995.

\section{Artículos de Revistas y Diarios}

Biehl, John.

Entrevista del diario Estrategia, lunes 15 de mayo de 1995.

Caryallo, Mauricio.

«La Próxima Negociación del NAFTA: Un Largo Laberinto», El Mercurio, domingo 18 de diciembre de 1994.

Confederación Sindical Unitaria El Surco. «NAFTA, Pequeña y Mediana Agricultura y Asalariados Agrícolas».

Central Unitaria de Trabajadores. Unión y Trabajo, Especial "La CUT y la CLC ante los Tratados de Libre Comercio", Marzo de 1997.

Corporación Tiempo 2000. Boletín de 20-24 de junio de 1994.

Embajada de Estados Unidos de América. Noticias Economicas. Servicio Informativo. «Principales Periódicos de EE.UU. Urgen al Congreso a Apoyar el Acuerdo de Libre Comercio de América del Norte», 14 de agosto de 1992.

Noticias Económicas. Servicio Informativo. «Resumen de los Acuerdos Complementarios delALCAN», 18 de agosto de 1993.

Cooper, Helene. The Wall Street Joumal, «En EE.UU. la Batalla del TLC No Tiene Ganadores ni Perdedores», en El Mercu* rio, martes 17 de junio de 1997.

Fernández, Alex.

En edición especial de El Mercurio, viernes 4 de julio de 1997.

«Un Camino Lento», El Mercurio, lunes 27 de octubre de 1997.

Fantuzzi, Roberto.

En edición especial El Mercurio, jueves 10 de julio de 1997.

Feulner, Edwin. En entrevista de El Mercurio,

25 de mayo de 1997, p. D 21.
Fishlow, Albert.

En entrevista de El Mercurio, martes 2 de septiembre de 1997

Garzón, Laura. "Area de Libre Comercio de las Américas: ¿Otro Volador de Luces?",

El Mercurio, domingo 16 de noviembre de 1997.

García, Claudio. En entrevista de revista Administración y Economía, Pontificia Universidad Catolica de Chile, Santiago.

Hachette, Dominique. "La Liberalización Comercial", Administración y Economía, No. 22, invierno de 1995.

Katz, Julius.

En entrevista de El Mercurio, domingo 4 de noviembre de 1994.

Labán, Raúl, Felipe Larraín y Jorge Quiroz. «La Agricultura Chilena Frente al NAFTA y al Mercosur, Administración y Economia, Núm. 22, invierno de 1995.

Luxner, Larry. "USA vs USA", América Economía, 1997.

Moffet, Matt. «La Legislación Laboral de Chile, Una Espina para Estados Unidos», artículo de The Wall Street Jouynal en El Mercurio, miércoles 15 de octubre de 1997.

Muchnik, Eugenia. «La Agricultura y la Agroindustria Frente a un Acuerdo de Libre Comercio con Estados Unidos», Panorama Económico de la Agricultura, Universidad Católica de Chile, año 16, Núm. 5, julio-agosto de 1996.

Time Magazine. «Upside Downside, The Benefits of Globalization: Could Be Jeopardized If Governments Fail to Address the Problems it Engenders», July 7, 1997.

Toro, Juan Pablo. «La Globalización, Un Proceso Irreversible», El Mercurio, domingo 19 de enero de 1997.

Venegas, Haroldo.

En edición especial de El Mercurio, jueves 10 de julio de 1997.

Visión. «Ün Sitio en la Historia del Comercio», enero de 1997.

YThelan, James. «LLe Conviene a Chile Un Tratado de Libre Comercio con los EE.UU.?', El Mercurio, domingo 28 de agosto de 1994.

United States Government, Whitehouse. Fast Track. hitp: www. whitehouse.gov. 


\section{Discursos}

Baughman, Laura. Trade Partnership. Charla "La Discusión y Elaboración de la Política Comercial en el Congreso Norteamericano". Miércoles 15 de octubre de 1997. Instituto de Estudios Internacionales de la Universidad de Chile. (dictada en inglés).

Destler, I.M., en conferencia ofrecida en el Instituto de Estudios Internacionales de la Universidad de Chile. Julio de 1994.

\section{Siglas}

\author{
AFL-CIO: American Federation of Labor-Congress of \\ Industrial Workers. \\ ALC: Acuerdo de libre comercio. \\ ALCA: Acuerdo de Libre Comercio de las Américas \\ (proyecto para el año 2005).
}

AMCHAM: Cámara Chileno-Norteamericana de Comercio. ASEXMA: Asociación de Exportadores de Manufacturas. ASMIET: Asociación de Industriales Metalúrgicos.

CLC: Canadian Labor Congress.

CODEFF: Comité Pro Defensa Flora y Fauna.

CPC: Confederación de la Producción y el Comercio.

CUT: Central Unitaria de Trabajadores.

IEP: Instituto de Ecología Política.

NAAEC: North American Agreement on Environmental Cooperation.

NAALC: North American Agreement on Labor Cooperation. NAFTA: North American Free Trade Agreement (Tratado de Libre Comercio de América del Norte).

PEPALC: Programa de Estudios del Sector Privado para un Acuerdo de Libre Comercio con Estados Unidos.

RECHIP: Red Chilena de una Iniciativa de los Pueblos.

RENACE: Red Nacional Ecológica.

SGP: Sistema Generalizado de Preferencias.

SNA: Sociedad Nacional de Agricultura.

SOFOFA: Sociedad de Fomento Fabril.

TLC: Tratado de libre comercio (en general), término con el cual también se ha hecho referencia al NAFTA.

USTR: United States Trade Representative. 